\title{
The Cost of Cancer: The Association of Financial and Cancer-Related Stress on Maladaptive Coping Styles in Families with a Cancer Diagnosis
}

\author{
Emily M. Johnson ${ }^{1}\left[\right.$. Donald Bruce Ross ${ }^{1}[$ ] \\ Accepted: 30 June 2021 \\ (c) The Author(s), under exclusive licence to Springer Science+Business Media, LLC, part of Springer Nature 2021
}

\begin{abstract}
According to the American Cancer Society (2020), it is estimated that 1.8 million new cancer diagnoses will occur in 2019 in the United States. Due to the frequency of cancer diagnoses and the increasing costs of treatment, financial stress is common among cancer patients. Guided by the Family Systems Illness Model (FSI), a cross-sectional study of individuals and family members where there was an active cancer diagnosis $(n=53)$ was conducted. The study utilized structural equation modeling to examine the impact of cancer stress and financial stress on maladaptive family coping mechanisms, and in turn, their effect on family communication and satisfaction. Findings indicate individuals with higher financial stress reported greater cancer stress. In turn, individuals with higher cancer stress, reported higher rigidity in their family coping which was associated with less family satisfaction. Additionally, as individuals reported greater family disengagement and chaos, lower levels of family communication and satisfaction were found. These findings provide evidence to the complex stresses experienced by cancer patients and their families. Therapeutic implications of how emotionally focused therapy may support these families dealing with a cancer diagnosis are discussed.
\end{abstract}

Keywords Cancer $\cdot$ Coping $\cdot$ Family finance $\cdot$ Finance $\cdot$ Financial counseling $\cdot$ Stress

\section{Introduction}

According to the American Cancer Society (2020), it is estimated that 1.8 million new cancer diagnoses will occur in 2019 in the United States. With the number of new yearly cancer diagnoses being alarmingly high, it is unsurprising to find out that there are over 16 million Americans living with cancer as of 2015 (American Cancer Society, 2020). Consequently, cancer remains one of the leading causes of death worldwide and affects individuals and families alike, increasing reported stress (Goswami \& Gupta, 2018; Laizner, 2018). Stress is defined as a physical, mental, and emotional response to life events placing threats on one's physical, emotional, or overall well-being (Cohen, Gianaros, $\&$ Manuck, 2016). In addition to stress, rates of depression, anxiety, and post-traumatic stress remain significantly high within family members who are affected by cancer, making

Emily M. Johnson

em.johnson@uky.edu

1 University of Kentucky, Lexington, USA cancer stress specifically unique (Goswami \& Gupta, 2018). As cancer affects the family, roles within the family shift (e.g., transitioning to a caregiving relationship), influencing each family member to adapt to the process (Laizner, 2018).

A cancer diagnosis not only creates stress within the family, but the sheer costs of treatment can have a devastating impact on a family (Amir et al., 2012; Balfe et al., 2016; Cagle et al., 2016). In 2017, the direct medical costs of cancer amounted to 147.3 billion US dollars, with the average patient paying roughly $\$ 150,000-\$ 300,000$ per year (American Cancer Society, 2020). Considering the outrageous costs associated with cancer care, it is clear to see how existing financial stress can add to cancer stress on the family, especially if the family is in a lower socioeconomic class or a part of a minority population. The American Cancer Society (2020) states that roughly 28.5 million Americans are uninsured, limiting a family or individual's ability to receive cancer care. This financial stress can, like cancer stress, cause family members to adopt new roles in order to keep the family system functioning (Goswami \& Gupta, 2018).

Cancer stress impacts everyone within the family system, and each individual's response to those stressors, in 
turn, affects the family system's roles and cohesion (Olson, 2000; Laizner, 2018; Areia et al., 2019; Bouchal et al., 2015). Uncertainty concerning the illness timeline and new onset of disabilities as the illness progresses can compound the stress a family system experiences (Sieh et al., 2012; Rolland, 1994, 1999, 2004). Considering the changes that families coping with cancer go through, it is not surprising that family cohesion, as well as the ability to communicate, dissolves under extreme stress (Olson, 2000; Bouchal et al., 2015; Kulkarni et al., 2014; Laizner, 2018). Rolland (1999) created the Family systems illness model (FSI) to explain changes families coping with illness face. Family systems illness model (FSI; Rolland, 1994, 1999, 2004) provides a framework for understanding how family systems adapt to change over time in the context of illness (Bowen, 1993; Walsh, 2012). The purpose of the present study examines the effect of financial stress and, in turn, cancer stress on maladaptive family coping mechanisms and their association family communication and satisfaction.

\section{Theoretical Framework}

Examining theoretical frameworks used in the present study, it is important to understand the basics of the theoretical study of families as a system. Murray Bowen noted the importance of the effects that family members have on one another, due to the fact that they share a history and a future (Bowen, 1993; Walsh, 2012). After studying system theories by Ludwig von Bertalanffy and the patterns of connection from Gregory Bateson, Bowen inferred that families work together as a system, and not simply as individual moving parts (Bowen, 1993; Walsh, 2012). After other researchers, such as Minuchin and Kerr began to apply this theory in research, and in practice, Family Systems theory became the dominant theory to analyze families (Kerr, 1981; Minuchin, 1985). Furthering this idea, John Rolland adapted Family Systems theory to an illness in the family, studying how the family system adapts and changes when a member of the system falls ill (Sieh et al., 2012; Rolland, 1999, 2004; Olson, 2000). In the present study, each theory is discussed in the context of cancer diagnoses in families, and the associated cancer and financial stress.

Cancer can have a devastating impact on the family system and Family Systems Illness Model (FSI) is integral for understanding the effects illness has on a family (Rolland, 1999, 2004; Rolland et al., 2017; Olson, 2000). The FSI measures family reactions to stressors caused by illness over time, consistently using family as the interactive focal point of the processes (Sieh et al., 2012; Rolland, 1994). Additionally, the FSI keeps track of how the family interacts with its environment (e.g., the healthcare system; Rolland, 1994) in response to the stressor. Rolland $(1999,2004)$ and Rolland et al. (2017) examines the goodness of fit between the psychosocial demands brought on by the terminal illness, and how the family functions within the limits of the illness. The main focus of the FSI is to track the systematic interaction between the family and the illness-induced stress. The family systems illness model provides an extensive framework for the reorganization of families during the time of illness, paving the way to allow researchers to understand the challenges that families face when coping with illness.

\section{Literature Review}

\section{Financial Stress Effecting Families Coping with Cancer}

When a family is coping with a cancer diagnosis, the potential financial stress may not be immediately realized (Amir et al., 2012; Balfe et al., 2016). The initial diagnosis tends to overwhelm families and patients alike, especially as cancer is often perceived as a death sentence (Hamel et al., 2016). Cancer treatment is costly, and with the scope of insurance coverage, it is not uncommon for families to pay out-ofpocket for cancer treatments, potentially depleting their savings (Cagle et al., 2016). Cagle et al. (2016) found that one-third of the participants reported spending most or all of their life savings to pay for cancer treatments, exemplifying the devastating financial burden cancer treatment can have on a family.

Although out-of-pocket costs are considered a consequential financial burden (Balfe et al., 2016), other aspects of day-to-day life can also contribute to financial stress. Specifically, the loss of employment by the patient and caregiver(s), as well as the reduced number of hours worked by family members to spend time with their loved one (Amir et al., 2012; Forbat, McManus, \& Haraldsdottir, 2012; Grable et al., 2020), all contribute to a significant loss of income during the times of illness (Balfe et al., 2016). Issues with employment lead patients and their family members have fewer opportunities to maintain a steady flow of income, furthering the financial burden on the family. Many cancer patients will struggle to return work, and at times the absence itself can lead to job loss, lowering the family's financial stability significantly (Archuleta et al., 2020; Ford et al., 2020; Grable et al., 2020; Hamel et al., 2016).

Although treatment costs clearly have a profound impact on families, it is crucial to note that financial stress is not necessarily as devastating for the majority of families. Most families found that they struggled with simply losing daily luxuries, such as letting go of a premium subscription to a cable company, in order to save money (Amir et al., 2012). This financial stress can also lead to families struggling to pay for their children's extracurricular activities and 
educational opportunities. (Gale et al., 2020; Knight et al., 2018). Following a cancer diagnosis, the financial stress generally causes lifestyle and role changes within the family, however, there is little research regarding the effect that financial stress has on family cohesion and functioning.

\section{Stress Associated with Cancer}

With each family member responding to stressors individually, this can create conflict within the family, affecting family cohesion as a whole (Areia et al., 2019). Each family member often takes on a new role within the family after a cancer diagnosis, ranging from caregiver to new primary breadwinner, a second caregiver to siblings, etc. These new roles likely send families into crisis, strengthening the likelihood that family cohesion will decrease, due to the family's struggle with adaptability (Goldblatt, Granot, \& Zarbiv, 2019). Various forms of cancer stress are associated with adapting to a cancer diagnosis, such as depression, anxiety, guilt, shame, and anger, greatly affect each individual's and family's ability to adapt to the diagnosis and create functioning support for one another (Sieh et al., 2012; Walsh, 2012).

\section{Family Cohesion as a Coping Mechanism}

\section{Effects on Family Function}

Each family experiences illness uniquely as they navigate the symptoms and suffering associated with a family member's illness (Olson, 2000; Walsh, 2016). When looking at cancer through the lens of the FSI, it is important to acknowledge three distinguishing facets to family functioning: the phase of the family life cycle and cohesion required, the alteration of structure in life phases of the family, and periods of higher or lower psychosocial demands caused by the illness (Rolland, 1994, 2004). For example, if the family is in the early stages of the family life cycle, there will be a period of grieving the life goals that may never be achieved, particularly those surrounding parenting and childrearing (Rolland, 1999, 2004). Considering both ends of the life cycle, there are a variety of challenges that come with illness in each section of the lifespan. Regardless of the life cycle stage, a cancer diagnosis introduces new stressors to the family system, which can lead to lower levels of cohesion (Rolland, 1999, 2004).

Rolland $(1999,2004)$ notes that in the FSI, it is important to gain an understanding of the family's response to past crises to gauge how the family will cope with the current illness. Because a terminal illness is considered a moderate to severe crises for families, it is extremely important for the family to adapt and restructure itself quickly, accommodating new life changes with this illness and its anticipatory outcome (Rolland, 1994, 2004). When viewing a past record of how families reorganize in crises related to illness, it becomes much easier to track and predict common coping strategies and the skills that have been ingrained within the family.

When a family is coping with cancer, commonly, one or multiple family members will often take on the role of caregiver, which can be accompanied by great distress (Haley et al., 2002). Evidence is shown that the stress of the family member's role as a caregiver can depend on race, culture, ethnicity, and social support (Haley et al., 2002). Due to different expectations within cultures, some are more apt to take care of their terminally ill loved ones, rather than others. This also ties into relationships, such as who will head the house after a parent pass. In some cultures, after the passing of the father, his son, no matter the age, may feel responsible to take on a fatherly role within the family. Various different members of the family will begin to feel as if they need to reorganize functioning, preparing for the impending loss of a loved one, which is often the most difficult part of the process. The diagnosis affects the couple relationship and family subsystems as well (Story et al., 2018).

When considering the FSI, one must notice the formation of new roles in the family, and how the potential of death can impact each family member in the span of the illness (Haley et al., 2002). Research conducted at Sloan Kettering Memorial Hospital (Pessin, Rosenfeld, \& Breitbart, 2002), found that psychological aspects, such as depression, can have the strongest effect on families and patients during the terminal stage of illness. Depression is commonly found in both family members and the patient as they reach the end of their road with a terminal illness (Areia et al., 2019; Pessin et al., 2002). At the end of life, much of the depression experienced by both the patient and the family is due to loss of autonomy, loss of health, and the loss of a loved one from the family system (Edwards \& Clarke, 2004; Areia et al., 2019). In addition, the level of uncertainty accompanying the illness can greatly impact anxiety levels within family members, adding on to the burden of likely depression (Rolland, 1999). Pessin, Rosenfeld and Breitbart (2002) found that levels of anxiety greatly depend on the level of control and mastery that the family feels they have when coping with the illness and its effects. This anxiety is greatly affected by the family's belief system about the illness, and how prepared they feel to cope (Rolland, 1994, 1999, 2004). If a family is struggling to process an illness and its implications, the level of anxiety within the family is much likely to be higher. Tying this idea of anxiety into the FSI, the lack of certainty of the trajectory of the illness greatly increases anxiety within the family and decreases family functioning. 


\section{The Current Study}

When considering the varying effects that cancer can have on the family system, it is necessary to examine the relationship between financial stress and cancer stress, and how that relates to maladaptive family behaviors. The purpose of the current study is to examine the connection between cancer stress and financial stress, and their impact on maladaptive family coping mechanisms, and in turn, their association with family communication and satisfaction. The present study tests three hypotheses:

(1) Participants reported financial stress will be positively and significantly related to reported cancer stress.

(2) Higher levels of participant reported cancer stress will be positively and significantly related to reported levels of maladaptive family characteristics (enmeshment, rigidity, disengagement, and chaos).

(3) In turn, higher levels of maladaptive family characteristics will be negatively and significantly related to reported levels of family satisfaction and family communication.

\section{Method}

\section{Participants}

To qualify for the present study, an individual must have a cancer diagnosis or have a member of the family with a cancer diagnosis. Participants were recruited from hospitals, the Cancer Support Community network, as well as social media platforms, such as Facebook. Participants were also gathered with the snowball effect, as current participants and organizations were encouraged to inform others about this study. The participants completing the survey were required to be over the age of 18 within the participating families. In order to recruit participants, flyers to sign up for the study were distributed to various cancer support groups, displayed in hospitals, and emailed in newsletters via the Cancer Support Community. The flyer provided information about the study, a QR code to provide easy access to the Qualtrics survey, as well as the researcher's contact information to answer further questions. Participation in this study was completely voluntary, giving participants the ability to stop at any time point in the study. All study procedures were approved by the University of Kentucky IRB.

\section{Demographic Characteristics}

Each participant completed a series of questions to define the demographics of this study. Specifically, these items will focus on the participant's age, race, sex, marital status, financial status, and education status (Hamel et al., 2016). The financial status items will be used to capture information about their ability to meet their expenses both before and since the diagnosis. The participants were asked questions regarding their cancer diagnosis, such as the stage of cancer, when they were diagnosed, where they are in treatment, and their medical insurance provider.

Of the initial 84 participants who started the study, 53 of the participant data were utilized due to missing date. Missing data was likely due to the lengthy nature of the survey. Out of all participants in the current sample, 93.4\% $(n=50)$ identified as Caucasian, 1.9\% $(n=1)$ identified as Hispanic, and 3.8\% ( $\mathrm{n}=2)$ identified as Asian. Additionally, $46.3 \%$ of the sample was between 84 and $75,52.6 \%$ was between 70 and 41 , and $1.1 \%$ was between 40 and 28 , with the youngest participant being 28 . The sample was primarily female at $64 \%$ of the participants identified as female, $34 \%$ as male, and $1.9 \%$ as other. Out of the sample $77.4 \%$ were married, over $60 \%$ of the participants had a Bachelor's degree or higher, and $77.4 \%$ of the participants identified as the patient, and 22.6 identified as a family member. $20.8 \%$ of participants experienced job loss or reduction of hours following a cancer diagnosis in themselves or family member. Roughly $50 \%$ of the sample reported that they had another family member who had also been diagnosed with cancer. Nearly $50 \%$ of the participants made over $\$ 75,000$, and the $77.3 \%$ of the participants had less than $\$ 25,000$ of debt. $9.4 \%$ of the sample reported having $\$ 100,000+$ in debt. The demographic data is displayed in Table 1.

\section{Measures}

The participants were given a three-part questionnaire to complete. The first two sections of the questionnaire are the Response to Stress Questionnaire (RSQ), specifically the RSQ for financial problems and for cancer stress (ConnorSmith \& Compas, 2004). After completing both sections of the RSQ, the participants then completed the Family Adaptability and Cohesion Scale IV (FACES IV) to measure family cohesion and well-being (Olson, 2000; Franklin, Streeter, \& Springer, 2001).

\section{Response to Stress Questionnaire-Finance Version}

Questions measuring coping within the RSQ-Finance Version (FV) are presented as "When I am trying to sleep, I can't stop thinking about the stressful aspects of money problems or I have bad dreams about money problems," or 
Table 1 Demographic characteristics of participants $(\mathrm{N}=53)$

\begin{tabular}{|c|c|c|}
\hline Characteristic & $n$ & $\%$ \\
\hline \multicolumn{3}{|l|}{ Gender } \\
\hline Woman & 34 & 64.2 \\
\hline Man & 18 & 34.0 \\
\hline Other & 1 & 1.9 \\
\hline \multicolumn{3}{|l|}{ Race or ethnicity } \\
\hline White & 50 & 94.3 \\
\hline Black & 0 & 0 \\
\hline Hispanic & 1 & 1.9 \\
\hline American Indian or Alaskan Native & 0 & 0 \\
\hline Native American & 0 & 0 \\
\hline Asian & 2 & 3.8 \\
\hline Other & 0 & 0 \\
\hline \multicolumn{3}{|l|}{ Age (years) } \\
\hline $28-40$ & 7 & 46.3 \\
\hline $41-70$ & 26 & 52.6 \\
\hline $75-84$ & 19 & 1.1 \\
\hline \multicolumn{3}{|l|}{ Marital status } \\
\hline Single & 4 & 7.5 \\
\hline Dating/courting & 3 & 5.7 \\
\hline Married & 41 & 77.4 \\
\hline Divorced/separated & 4 & 7.9 \\
\hline Other & 1 & 1.9 \\
\hline \multicolumn{3}{|l|}{ Education } \\
\hline Less than high school degree & 1 & 1.9 \\
\hline High school degree/equivalent & 2 & 5.7 \\
\hline Some college, no degree & 12 & 22.6 \\
\hline Associate degree & 2 & 3.8 \\
\hline Bachelor degree & 15 & 28.3 \\
\hline Professional degree & 6 & 11.3 \\
\hline Graduate degree & 15 & 28.3 \\
\hline
\end{tabular}

"My mind just goes blank when something stressful happens related to money problems, I can't think at all." These questions determine the behaviors surrounding financial stress. In previous studies completed in related topics, generally showing $\alpha=0.71$ (Wadsworth \& Compas, 2002). In the current study, the RSQ-FV shows high internal consistency $(\alpha=0.73)$.

\section{Response to Stress Questionnaire-Cancer Stress}

Within the RSQ, participants completed the questionnaire measuring the stress levels associated with witnessing a family member struggle with cancer. Each participant will be given the RSQ measuring stress of cancer and family financial troubles. The RSQ for cancer and financial stress each contain 57 items. The RSQ uses a Likert-type scale ranging from not at all (scored as 1) to a lot (scored as 4). RSQCancer Stress (CS) uses questions to scale perceived stress and coping behaviors. For example, on the RSQ-CS asks, "I do something to try to fix the stressful parts of having (a family member with) cancer." Not only does this questionnaire measure the levels of stress, but it also asks the participants to write their coping mechanisms as well. Higher scores indicate higher reported stress levels. The RSQ has been adapted to various stressors to analyze stress levels. In previous use, the RSQ has $\alpha=0.71$ for the majority of the variations of the questionnaire (Connor-Smith \& Compas, 2004). The RSQ-Cancer Stress had high internal consistency $(\alpha=0.92)$ in the current study.

\section{Family Adaptability and Cohesion}

FACES IV is a 62-item questionnaire that measures family cohesion and well-being. FACES IV is measured using response options ranging from very dissatisfied (reported as 1) to extremely satisfied (measured as 5). This survey uses questions to report family cohesion within specific family interactions. For example, FACES IV will ask questions such as: "Family members seem to avoid contact with each other when at home," and "Our family becomes frustrated when there is a change in plans or routines." Each question scales the family's ability to adapt to change, measure how tasks are completed, and note boundaries within the family system. FACES IV is a commonly used assessment, providing high levels of validity and reliability (Franklin et al., 2001). When scoring FACES IV, higher scores indicate higher reported family adaptability and cohesion, while lower scores indicate more maladaptive family behaviors. FACES IV is divided into subscales, measuring cohesion, flexibility, disengagement, enmeshment, rigidity, chaos, satisfaction, and communication. FACES IV is a commonly used assessment, providing high levels of validity and reliability (Franklin et al., 2001). In the current study, the FACES IV subscales all showed high internal consistencies with $\alpha \mathrm{s}>0.83$ for each subscale.

\section{Procedure}

Before beginning the study, each participant was given an informed consent which highlights the risks and issues of confidentiality. After signing the informed consent, the participants were given a three-part survey to complete, measuring their cancer and financial stress as a family. The survey was not distributed to children, as this study measured the participants view of their own coping, and family coping. Next, each participant filled out the survey. The survey was delivered online via Qualtrics administered via email or via the QR code presented on the recruitment flyer in order to allow the participants to access the survey anywhere. Each participant was thanked for their participation in the survey 
and be given an option to enter a drawing to win $\$ 150$, per 50 participants.

\section{Analytical Strategy}

The current study utilized a path analysis examining the relationship between existing financial stress and its effects on cancer stress in families coping with cancer, and how maladaptive FACES are negatively related to family satisfaction and communication. Preliminary analyses examine a bivariate correlational matrix across all study variables. Data was collected with SPSS 25 (IBM Corporation, 2016) and analyses were run through AMOS 24.0 (Arbuckle, 2014) to obtain estimates. Participants were removed if they did not meet a missing data threshold of at least $25 \%$. Full information maximum likelihood (FIML) was used to account for missing data. FIML is preferable to other methods because it allows all available data to be utilized when estimating model parameters and standard errors (Enders \& Bandalos, 2001). Standardized coefficients were reported in analyzes. A range of fit indices was used to assess the goodness-offit, including the $\chi^{2}$ statistic/degrees of freedom ratio, comparative fit index (CFI), and the Root Mean Square Error Approximation (RMSEA). Measures of income, debt, and overall health were accounted for in analyses as control variables. These controls were chosen due the affect the amount of income and debt could have on general financial stress levels, potentially skewing the outcome results. Additionally, the present study controls for over-all health as well, assuming that if one's health is lower quality in general, this could also skew the outcome data.

\section{Results}

\section{Preliminary Analysis}

Associations to note, RSQ Finance and RSQ Cancer Stress displayed a statistically significant relationship $(p<0.001)$, meaning that if a participant was experiencing financial stress, that likely exasperated the cancer stress. FACES rigidity was positively associated with Cancer Stress $(p<0.001)$, meaning that if family members are experiencing cancer stress, they are likely to behave in a rigid manner. All correlations are listed in Table 2.

\section{Structural Equation Modeling}

Structural Equation Modeling (SEM) was used to assess the relationships among financial stress, cancer related stress, and family adaptability and cohesion. Figure 1 shows the standardized path coefficients for the SEM for participants. The model fit indices were as follows: $\chi^{2}(90-62)=28$, $p<0.001$; RMSEA $=0.032 ; 95 \%$ CI $[0,0.113]$; CFI $=0.995$; TLI 0.985. $\chi^{2} / \mathrm{df}=1.053$. Significant pathways are shown. RSQ Finance and RSQ Cancer Stress were significantly and positively associated with one another $(\beta=0.713, p<0.001)$, respectively. FACES rigidity was significantly and positively

Table 2 Bivariate correlations

\begin{tabular}{|c|c|c|c|c|c|c|c|c|c|c|c|c|}
\hline & 1 & 2 & 3 & 4 & 5 & 6 & 7 & 8 & 9 & 10 & 11 & 12 \\
\hline \multicolumn{13}{|l|}{ 1. FACES Disengagement } \\
\hline 2. FACES Enmeshment & .210 & & & & & & & & & & & \\
\hline 3. FACES Rigidity & .171 & $.409 * *$ & & & & & & & & & & \\
\hline 4. FACES Chaos & $.732 * * *$ & .211 & .234 & & & & & & & & & \\
\hline 5. Family Communication & $-.852 * * *$ & -.233 & -.250 & $-.740 * * *$ & & & & & & & & \\
\hline 6. Family Satisfaction & $-.853^{* * *}$ & -.221 & $-.363 * *$ & $-.735^{* * *}$ & $.927 * * *$ & & & & & & & \\
\hline 7. Cancer Stress & .036 & .114 & $.431 * * *$ & .054 & .076 & -.048 & & & & & & \\
\hline 8. Financial Stress & .003 & -.103 & .249 & .121 & -.044 & -.132 & $.766^{* * *}$ & & & & & \\
\hline 9. Education & -.236 & -.119 & -.252 & $-.288^{*}$ & .188 & .241 & $-.388 * *$ & $.466 * *$ & & & & \\
\hline 10. Debt & -.147 & -.065 & -.065 & -.045 & .154 & .116 & .079 & .216 & .133 & & & \\
\hline 11. Overall Health & -.171 & .102 & -.154 & -.196 & .166 & .189 & $-.301^{*}$ & $-.369 *$ & $.473 * * *$ & -.021 & & \\
\hline 12. Patient/Caregiver & -.134 & .000 & $.321 *$ & .012 & .034 & .032 & $.382 * *$ & .267 & -.107 & -.084 & .183 & \\
\hline Mean & 2.06 & 1.73 & 2.32 & 1.98 & 3.92 & 3.59 & 2.13 & 1.85 & 4019.61 & 1.98 & 3.53 & 3.76 \\
\hline Std Deviation & .823 & .537 & .679 & .736 & .930 & .961 & .406 & .438 & 1760.50 & 1.54 & .911 & .964 \\
\hline Skewness & 1.71 & .471 & .221 & .625 & -1.32 & -.915 & .090 & .057 & .333 & .333 & .327 & .334 \\
\hline Range & 3.57 & 2.14 & 2.86 & 2.71 & 4.00 & 4.00 & 1.66 & 1.81 & 5000.00 & 5.00 & 3.00 & 2.00 \\
\hline Range Min & 1.14 & 1.00 & 1.00 & 1.00 & 1.00 & 1.00 & 1.40 & 1.00 & 1000.00 & 1.00 & 2.00 & 1.00 \\
\hline Range Max & 4.71 & 3.14 & 3.86 & 3.71 & 5.00 & 5.00 & 3.06 & 2.81 & 6000.00 & 6.00 & 5.00 & 3.00 \\
\hline
\end{tabular}

$* * * p<.001, * * p<.01$, and $* p<.05$ 


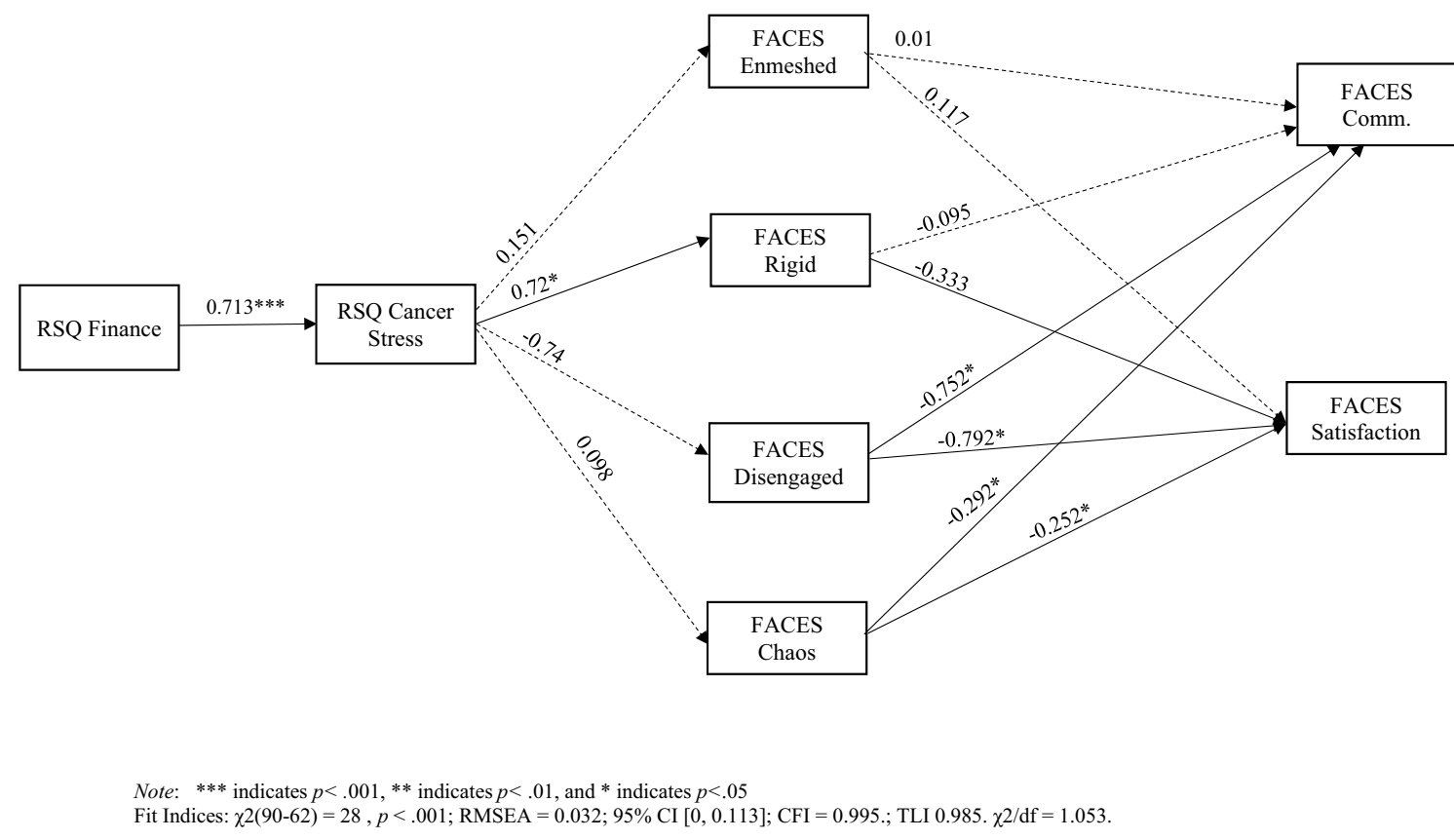

Fig. 1 Structural Equation Model. Note ${ }^{* * *} p<.001, * * p<.01$, and $* p<.05$. Fit Indices: $\chi^{2}(90-62)=28, p<.001 ;$ RMSEA $=0.032 ; 95 \%$ CI $[0$, $0.113]$; CFI $=0.995 ;$ TLI $0.985, \chi^{2} / \mathrm{df}=1.053$

associated with Cancer Stress $(\beta=0.72, p<0.001)$, respectively, meaning that if a participant presented with higher levels of cancer stress, rigidity was more likely. FACES rigid was significantly and negatively associated with family satisfaction $(\beta=-0.333, p<0.001)$, meaning the more rigidity reported, lower amounts of family satisfaction were reported as well. Family communication was significantly and negatively associated with disengagement $(\beta=-0.752$, $p<0.001$ ), respectively, meaning that lower reported communication is related to higher levels of reported disengagement. FACES Chaos was significantly and negatively associated with family communication $(\beta=-0.292, p<0.002)$, respectively, meaning that lower reported levels of communication are related to higher levels of chaos. Disengagement was significantly and negatively associated with family satisfaction $(\beta=-0.792, p<0.001)$, respectively, meaning that higher reported levels of disengagement is related to lower levels of family satisfaction.

\section{Discussion and Implications}

The present study extends the literature by investigating the connection between cancer stress and financial stress, and how each is related to maladaptive family coping mechanisms. By studying family adaptability and cohesion via FACES IV, the present study measured overall family coping skills, and how these coping skills are each affected by financial and cancer stress. These maladaptive coping skills are related to the family's reported levels of communication and satisfaction.

The model utilized in the present study examined the connection between cancer stress and financial stress, and how each is related to maladaptive family coping mechanisms. This model produced significant pathways between financial and cancer stress, cancer stress and rigidity, rigidity and family satisfaction, and disengagement and family satisfaction and communication. The main factors showing significance were with rigidity and disengagement being negatively associated with family satisfaction and communication. Out of all of the factors, rigidity appeared to have the most connections in number, with relationships to financial stress and cancer stress, as well as family communication and satisfaction. This is likely due to the experienced role changes and family reorganizations explained in the FSI after the initial cancer diagnosis (Rolland, 2004). With various changes occurring in a family at once, each individual family member is likely to become rigid in a way to maintain a sense of stability, which would explain the higher levels of rigidity in this population.

Hypothesis one states participants reported financial stress will be positively and significantly related to reported cancer stress. This hypothesis was shown to be significant within this data, meaning that if a family has existing financial stress, the participants often reported higher levels of cancer stress, which was confirmed through the reported relationship between financial stress and cancer stress, unsurprisingly. This finding lends evidence to supporting 
previous literature stating that existing financial stress increases cancer stress due to high cancer treatment costs (Knight et al., 2018).

Hypothesis two states higher levels of participant reported cancer stress will be positively and significantly related to reported levels of maladaptive family characteristics (enmeshment, rigidity, disengagement, and chaos). This hypothesis was confirmed through the significant pathway shown between cancer stress and rigidity, showing that with cancer stress, a family will behave in a more rigid manner in order to maintain control. Role reorganization is a critical aspect of the FSI, making the finding that cancer stress and rigidity are associated, due to the likely resistance to role change. When a family is coping with an illness, there is often need of role reorganization, often forcing family members to take on unfamiliar roles. Often, during role reorganization within the family system, family members are forced to take on roles that they are not used to, or are not comfortable in. With the likely aversion that family members feel when changing roles, this is much more likely to increase rigidity within the family system. Additionally, a cancer diagnosis and treatment process bring change within the family system, likely leading families to increase rigidity due to the resistance of change.

Hypothesis three states higher levels of maladaptive family characteristics will be negatively and significantly related to reported levels of family satisfaction. This hypothesis was confirmed by significant connections between rigidity and family satisfaction, as well as disengagement and family communication and satisfaction. These findings are important because this signifies possible relationships with family communication and satisfaction in relation to the family's coping skills. When looking at the results, it is show that there is a relationship between maladaptive coping skills and decreased family communication and satisfaction. This is likely due to the fact that when a family is disengaged, they are much more likely to have decreased communication and satisfaction. Because families likely increase rigidity in response to role changes within the family system, family satisfaction will likely go down due to the fact that there is a lack of flexibility and adaptability in the family system. Talk about how role changes could be negatively affecting the family. Cancer treatment lowers satisfaction and increases stress, similar to rigidity. Disengagement is decreasing family communication and satisfaction. Important because exacerbating stress that they already feel.

\section{Limitations}

Limitations in the present study provide guidelines for future research directions. The current study employs a cross-sectional research design, meaning that the findings should not be interpreted from a causal perspective. A longitudinal analysis would benefit future studies to examine how the study's constructs change over time. Additionally, the small sample size should be taken into account and used with caution in interpreting the results. Although an exploratory study with an initial 84 participants, only 53 participants completed enough data to use in the analysis. The high degree of missing data can be attributed to the length of the survey, as many participants reported that they did not have the time to complete it entirely. Additionally, an a priori statistical power analysis using $\mathrm{G}^{*}$ Power (Faul et al., 2009) - based on an alpha ( $\alpha$ ) of .05, a beta ( $\beta$ ) of .20, a medium effect size (f2) of .15 (Cohen, 1988), and seven predictor variables-yielded a recommended sample size of 103. The current study's sample size increases the margin of error, and thus the findings warrant caution in generalizing to a larger population of families managing a cancer diagnosis. Although the intention was to collect a greater sample size, the spread of COVID-19 forced the study to be closed earlier than expected to avoid collecting biased results. Consequently, future studies with a greater sample size are suggested. Lastly, the study may have been limited in the representatives of the sample as the majority of participants were white, married, and well-educated. Future studies should include a more diverse sample.

\section{Implications}

\section{Theoretical}

When examining the results from this study, at the very least, there are indications of stress levels, both emotionally and financially, when given a cancer diagnosis. In John Rolland's Family Systems Illness Model, higher stress levels are predicted due to the diagnosis. Participants in the present study did report higher levels of stress, which were related to the cancer. The present study hypothesized that with existing financial stress, cancer stress would likely be exasperated, relating to negative coping skills, which would have a negative relationship with family satisfaction and communication. When viewing the family from systems theory and the FSI, reorganization of the family structure can cause stress, which participants reported in the present study. The implications of the data found in the present study show that there are statistically significant stress levels in this population, and that future research must be conducted in order to gain more breadth when understanding stress levels and potential coping mechanisms.

\section{Clinical}

With the present implications in mind, financial family therapy could be a beneficial and integral part of cancer care, benefitting both the patient and their family. A therapeutic 
model called Emotionally Focused Therapy, that is often used with couples, has been tested on couples facing illness, such as cancer. Emotionally Focused Therapy (EFT) puts a heavy emphasis on creating a safe space to express underlying emotions, and address attachment insecurities (Ford et al., 2020; Tie \& Poulsen, 2013). Because the process of coping with illness and grief is generally a traumatic experience for the family, and attachment bonds within the family come to the forefront, EFT is thought to be a successful therapeutic intervention option for families, especially if they are anticipating death due to illness. The literature discusses that illness can often activate the attachment system, causing one to return to their internal working model (Tie \& Poulsen, 2013; Giese-Davis et al., 2002; Greenberg, 2012; Gale et al., 2020). In a study conducted with 16 couples, one suffering from terminal cancer, were to attend 8 sessions of EFT, and were tested both before and after for hopelessness, depression, and marital adjustment (Tie \& Poulsen, 2013). The outcome of this study displayed varying levels of depression significantly decreased within the patient, and moderately decreased within the spouse as well (Tie \& Poulsen, 2013). Because EFT creates a safe space for couples to express emotions, the idea noted is that the improvement in communication brought the couples to a more secure attachment, comforting one another through the anticipated grief of the loss (Greenberg, 2012; Ford et al., 2020). This same space created by EFT to express emotions, ideally, would be very effective when working with families struggling with cancer.

Funding Funded through the Phil Richards Endowment.

\section{Declarations}

Conflict of interest There were no conflicts of interest.

\section{References}

American Cancer Society. (2020). Cancer facts and figures. The Society.

Amir, Z., Wilson, K., Hennings, J., \& Young, A. (2012). The meaning of cancer: Implications for family finances and consequent impact on lifestyle, activities, roles and relationships. Psycho-Oncology, 21,1167-1174. https://doi.org/10.1002/pon.2021

Archuleta, K. L., Mielitz, K. S., Jayne, D., \& Le, V. (2020). Financial goal setting, financial anxiety, and solution-focused financial therapy (SFFT): A quasi-experimental outcome study. Contemporary Family Therapy, 42(1), 68-76. https://doi.org/10.1007/ s10591-019-09501-0

Areia, N. P., Fonseca, G., Major, S., \& Relvas, A. P. (2019). Psychological morbidity in family caregivers of people living with terminal cancer: Prevalence and predictors. Palliative and Supportive Care, 17(3), 286-293. https://doi.org/10.1017/S1478951518000044
Balfe, M., Butow, P., O'Sullivan, E., Gooberman-Hill, R., Timmons, A., \& Sharp, L. (2016). The financial impact of head and neck cancer caregiving: A qualitative study. Psycho-Oncology, 25(12), 1441-1447. https://doi.org/10.1002/pon.4079

Bouchal, S., Rallison, L., Moules, N., \& Sinclair, S. (2015). Holding on and letting go: Families' experiences of anticipatory mourning in terminal cancer. OMEGA-Journal of Death and Dying, 72(1), 42-68. https://doi.org/10.1177/0030222815574700

Bowen, M. (1993). Family therapy in clinical practice. Jason Aronson (Text).

Cagle, J. G., Carr, D. C., Hong, S., \& Zimmerman, S. (2016). Financial burden among US households affected by cancer at the end of life. Psycho-Oncology, 25(8), 919-926. https://doi.org/10. 1002/pon.3933

Cohen, J. (1988). Statistical power analysis for the behavioral sciences $\left(2^{\text {nd }}\right.$ ed.). Lawrence Erlbaum Associates. ISBN 0805802835 .

Cohen, S., Gianaros, P. J., \& Manuck, S. B. (2016). A stage model of stress and disease. Perspectives on Psychological Science, 11(4), 456-463. https://doi.org/10.1177/1745691616646305

Connor-Smith, J. K., \& Compas, B. E. (2004). Coping as a moderator of relations between reactivity to interpersonal stress, health status, and internalizing problems. Cognitive Therapy and Research, 28(3), 347-368

Edwards, B., \& Clarke, V. (2004). The psychological impact of a cancer diagnosis on families: The influence of family functioning and patients' illness characteristics on depression and anxiety. PsychoOncology, 13(8), 562-576. https://doi.org/10.1002/pon.773

Enders, C., \& Bandalos, D. (2001). The relative performance of full information maximum likelihood estimation for missing data in structural equation models. Structural Equation Modeling: A Multidisciplinary Journal, 8(3), 430-457. https://doi.org/10.1207/ S15328007SEM0803_5

Faul, F., Erdfelder, E., Buchner, A., \& Lang, A. (2009). Statistical power analyses using $\mathrm{G}^{*}$ Power 3.1: Tests for correlation and regression analyses. Behavior Research Methods, 41(4), 1149_ 1160. https://doi.org/10.3758/BRM.41.4.1149

Forbat, L., McManus, E., \& Haraldsdottir, E. (2012). Clinical implications for supporting caregivers at the end-of-life: Findings and from a Qualitative Study. Contemporary Family Therapy, 34, 282-292. https://doi.org/10.1007/s10591-012-9194-6

Ford, M. R., Ellis, É. M., Goetz, J., Archuleta, K. L., Gale, J. E., Grossman, B., Grant, E., \& Gonyea, J. (2020). Depression and financial distress in a clinical population: The value of interdisciplinary services and training. Contemporary Family Therapy, 42, 5-14. https://doi.org/10.1007/s10591-019-09514-9

Franklin, C., Streeter, C., \& Springer, D. (2001). Validity of the FACES IV family assessment measure. Research on Social Work Practice, 11(5), 576-596. https://doi.org/10.1177/104973150101100503

Gale, J., Ross, D. B., Thomas, M. G., \& Boe, J. (2020). Considerations, benefits and cautions integrating systems theory with financial therapy. Contemporary Family Therapy, 42(1), 84-94. https://doi. org/10.1007/s10591-019-09518-5

Giese-Davis, J., Koopman, C., Butler, L. D., Classen, C., Cordova, M., Fobair, P., Benson, J., Kraem, H. C., \& Spiegel, D. (2002). Change in emotion-regulation strategy for women with metastatic breast cancer following supportive-expressive group therapy. Journal of Consulting and Clinical Psychology, 70(4), 916. https://doi.org/ 10.1037/0022-006X.70.4.916

Goldblatt, H., Granot, M., \& Zarbiv, E. (2019). "Death lay here on the sofa": Reflections of young adults on their experience as caregivers of parents who died of cancer at home. Qualitative Health Research, 29(4), 533-544. https://doi.org/10.1177/1049732318 800676

Goswami, S., \& Gupta, S. S. (2018). Cancer has almost a similar psychosocial impact on family caregivers as those of the patients; but 
are we doing enough for them? Indian Journal of Cancer, 55(4), 419. https://doi.org/10.4103/ijc.IJC_628_18

Grable, J. E., Archuleta, K. L., Ford, M. R., Kruger, M., Gale, J., \& Goetz, J. (2020). The moderating effect of generalized anxiety and financial knowledge on financial management behavior. Contemporary Family Therapy, 42, 15-24. https://doi.org/10.1007/ s10591-019-09520-x

Greenberg, L. S. (2012). Emotion-focused therapy: A clinical synthesis. Focus, 8(1), 32-42. https://doi.org/10.1176/foc.8.1.foc32

Haley, W., Allen, R., Reynolds, S., Chen, H., Burton, A., \& GallagherThompson, D. (2002). Family issues in end-of-life decision making and end-of-life care. American Behavioral Scientist, 46(2), 284-298. https://doi.org/10.1177/000276402236680

Hamel, L. M., Penner, L. A., Eggly, S., Chapman, R., Klamerus, J. F., Simon, M. S., Stanton, S. C. E., \& Albrecht, T. L. (2016). Do patients and oncologists discuss the cost of cancer treatment? An observational study of clinical interactions between African American patients and their oncologists. Journal of Oncology Practice, 13(3), 249-258. https://doi.org/10.1200/JOP.2016. 015859

Kerr, M. E. (1981). Family systems theory and therapy. Handbook of Family Therapy, 1, 226-264.

Knight, T. G., Deal, A. M., Dusetzina, S. B., Muss, H. B., Choi, S. K., Bensen, J. T., \& Williams, G. R. (2018). Financial toxicity in adults with cancer: Adverse outcomes and noncompliance. Journal of Oncology Practice, 14(11), e665-e673. https://doi.org/10. 1200/JOP.18.00120

Kulkarni, P., Kulkarni, P., Ghooi, R., Bhatwadekar, M., Thatte, N., \& Anavkar, V. (2014). Stress among care givers: The impact of nursing a relative with cancer. Indian Journal of Palliative Care, 20(1), 31. https://doi.org/10.4103/0973-1075.125554

Laizner, A. M. (2018). Family functioning and therapeutic interventions when a parent has cancer. In Quality of life among cancer survivors (pp. 169-182). https://doi.org/10.1007/978-3-31975223-5_11.

Minuchin, P. (1985). Families and individual development: Provocations from the field of family therapy. Child Development. https:// doi.org/10.2307/1129720

Olson, D. H. (2000). Circumplex model of marital and family systems. Journal of Family Therapy, 22(2), 144-167.

Pessin, H., Rosenfeld, B., \& Breitbart, W. (2002). Assessing psychological distress near the end of life. American Behavioral Scientist, 46(3), 357-372. https://doi.org/10.1177/000276402237769

Rolland, J. (1994). The psychosocial typology of illness. In J. Rolland (Ed.), Families, illness, and disability: An integrative treatment model (pp. 19-42). Basic Books.
Rolland, J. (1999). Parental illness and disability: A family systems framework. Journal of Family Therapy, 21(3), 242-266. https:// doi.org/10.1111/1467-6427.00118

Rolland, J. S. (2004). Cancer and the family: An integrative model. Cancer: Interdisciplinary International Journal of the American Cancer Society, 104(S11), 2584-2595. https://doi.org/10.1002/ cncr.21489

Rolland, J. S., Emanuel, L. L., \& Torke, A. M. (2017). Applying a family systems lens to proxy decision making in clinical practice and research. Families, Systems, and Health, 35(1), 7. https://doi. org/10.1037/fsh0000250

Sandler, I. N., Ayers, T. S., Wolchik, S. A., Tein, J., Kwok, O., Haine, R. A., \& Griffin, W. A. (2003). The Family bereavement program: Efficacy evaluation of a theory-based prevention program for parentally bereaved children and adolescents. Journal of Consulting and Clinical Psychology, 71(3), 587-600. https://doi.org/ 10.1037/0022-006X.71.3.587

Sieh, D., Dikkers, S., Visser-Meily, A., \& Meijer, L. (2012). Stress in adolescents with a chronically ill parent: Inspiration from Rolland's family systems-illness model. Journal of Developmental and Physical Disabilities, 24(6), 591-606. https://doi.org/10. 1007/s10882-012-9291-3

Story, M. R., Finlayson, B., Creger, L., \& Bunce, E. (2018). The impact of chronic health conditions as an underlying challenge on couple's wellbeing. Contemporary Family Therapy, 40, 318-325. https://doi.org/10.1007/s10591-018-9466-x

Tie, S., \& Poulsen, S. (2013). Emotionally focused couples' therapy with couples facing terminal illness. Contemporary Family Therapy, 35(3), 557-567. https://doi.org/10.1007/s10591-013-9238-6

Wadsworth, M. E., \& Compas, B. E. (2002). Coping with family conflict and economic strain: The adolescent perspective. Journal of Research on Adolescence, 12, 243-274. https://doi.org/10.1111/ 1532-7795.00033

Walsh, F. (2012). Mastering family challenges in serious illness and disability. In F. Walsh (Ed.). Normal family processes growing diversity and complexity (pp. 399-422). Guilford.

Walsh, F. (2016). Serious illness and disabilities. In F. Walsh (Ed.), Strengthening family resilience (pp. 265-295). Guilford.

Publisher's Note Springer Nature remains neutral with regard to jurisdictional claims in published maps and institutional affiliations. 